\title{
Consumo e digestibilidade de dietas formuladas com diferentes níveis de casca de café para vacas em lactação ${ }^{1}$
}

\author{
Fernanda Cipriano Rocha ${ }^{2}$, Rasmo Garcia ${ }^{3}$, Acyr Wanderley de Paula Freitas ${ }^{4}$, Alexandre \\ Lima de Souza ${ }^{5}$, Sebastião de Campos Valadares Filho ${ }^{3}$, Odilon Gomes Pereira ${ }^{3}$, João \\ Paulo Sampaio Rigueira ${ }^{6}$, Rafael Gonçalves Tonucci ${ }^{6}$, Gabriel Cipriano Rocha ${ }^{6}$ \\ 1 Projeto financiado pela Fundação de Amparo à Pesquisa do Estado de Minas Gerais (FAPEMIG). \\ 2 Doutora em Zootecnia. \\ ${ }^{3}$ Departamento de Zootecnia - UFV. Bolsista do CNPq. \\ ${ }^{4}$ Pólo Regional da Alta Paulista - APTA. \\ ${ }^{5}$ Departamento de Ciências Biológicas/Zootecnia - UFMT. \\ 6 Zootecnista, DZO/UFV.
}

RESUMO - Avaliaram-se o consumo e a digestibilidade aparente da dieta, a produção e composição do leite e a economicidade de dietas formuladas com quatro níveis de casca de café na MS total (0, 5, 10,15\% da MS) em substituição ao milho no concentrado. Foram utilizadas 12 vacas da raça Holandesa, distribuídas em três quadrados latinos 4 x 4, de acordo com o período de lactação. As dietas (isoprotéicas, $15,5 \%$ de PB) foram constituídas de $60 \%$ de silagem de milho e $40 \%$ de concentrado, com base na MS. O consumo de EE não foi alterado, mas os de MS, MO, PB, carboidratos totais (CT) e carboidratos não-fibrosos (CNF) e a concentração de NDT das dietas decresceram linearmente com adição de casca de café, elevando, também de forma linear, o consumo de FDN. As digestibilidades de MS, MO, PB, CT, FDN, CNF e a concentração de NDT das dietas reduziram linearmente com a adição de casca de café no concentrado. A produção de leite e as quantidades de gordura, proteína, sólidos totais, extrato seco desengordurado e suas concentrações no leite não foram alteradas pelos níveis de casca de café nas dietas. O saldo com alimentação por vaca e por litro de leite aumentou linearmente com o incremento de casca de café nas dietas. A substituição do milho do concentrado por casca de café pode ser feita em até 15\% da MS total da dieta.

Palavras-chave: composição químico-bromatológica, milho, concentrado, resíduo agroindustrial

\section{Intake and digestibility of lactating dairy cows fed diets containing coffee hulls}

\begin{abstract}
The objective of this trial was to investigate the effects of replacing corn by coffee hulls on intake, apparent digestibility, and milk production and composition of lactating dairy cows. Treatments contained one of the following four levels of coffee hulls: 0, 5, 10 or 15\% of the total dietary DM. Twelve Holstein dairy cows were blocked by days in milk and randomly assigned to three replicated 4 x 4 Latin squares. Diets were isonitrogenous averaging $15.5 \%$ of CP and composed by $60 \%$ of corn silage and $40 \%$ of concentrate on DM basis. Replacing corn with coffee hulls did not affect the intake of EE. However, intakes of DM, OM, CP, TC, and NFC as well as dietary TDN all decreased linearly with the inclusion of coffee hulls in the diet. Apparent total tract digestibilities of DM, OM, CP, TC, NDF, and NFC also reduced linearly by increasing the proportion of dietary coffee hulls. Conversely, NDF intake increased linearly when coffee hulls replaced corn in the diet. No significant differences on milk yield as well as yields and contents of fat, protein, total solids, and solids nonfat were observed by including coffee hulls in the diet. Feeding balances (milk yield gross income - feeding costs) per cow and per liter of milk both increased linearly by partially replacing corn with coffee hulls. It can be concluded that coffee hulls can replace up to $15 \%$ of the corn in the diet with no detrimental effects on production.
\end{abstract}

Key Words: by-product, chemical composition, concentrate, corn

\section{Introdução}

As mudanças econômicas ocorridas desde o início da década de 1990 comprovam rápidos ajustes estratégicos e estruturais do setor agroindustrial do leite. A desregulamentação do mercado do leite, posterior à abertura comercial da economia brasileira, resultou em um mercado bastante competitivo, exigindo produtividade, qualidade e escala de produção (Reis et al., 2001).

Um estudo desenvolvido pela Confederação da Agricultura e Pecuária do Brasil demonstra que, em 2001, o pecuarista precisava vender 716 litros de leite para comprar uma tonelada de milho, enquanto, em 2002, foram necessários 1.071 litros (OCB, 2003). 
A avaliação do valor nutritivo dos alimentos consumidos pelos animais tem sido um desafio para os nutricionistas. A variedade de alimentos utilizados na alimentação de ruminantes é muito grande, mas o valor nutricional de um alimento depende de uma complexa interação entre seus constituintes e os microrganismos do trato digestivo nos processos de digestão, absorção, transporte e utilização de metabólitos, além da própria condição fisiológica do animal. Para que o animal ruminante possa expressar seu potencial genético máximo, é necessário o fornecimento de níveis adequados de nutrientes por meio de uma ração balanceada (Dutra et al., 1997).

Nesse contexto, o preço dos concentrados pode ser fator limitante na alimentação de vacas, devendo o criador dispor de alternativas viáveis para minimizar os custos (Signoretti et al., 1997). Entre algumas opções de alimentos para o gado leiteiro, a casca de café pode ser uma alternativa.

A disponibilidade de resíduos agrícolas de baixo custo e a crescente preocupação com problemas ambientais tem gerado maior interesse quanto ao destino desses resíduos e ao possível aproveitamento na alimentação animal. Considerando que o estado de Minas Gerais detém uma das maiores e mais importantes bacias leiteiras do país e que, na safra de 2002/2003, produziu 52\% do café beneficiado no Brasil (ABIC, 2003), a utilização da casca de café na alimentação dos rebanhos leiteiros tem sido avaliada em vários estudos, tanto em substituição a alimentos volumosos (Townsend et al., 1998; Vilela, 1999) quanto a grãos de cereais (Barcelos et al., 1997), podendo ainda ser utilizada como aditivo na produção de silagens de gramíneas tropicais (Souza et al., 2003).

Os subprodutos são caracterizados como alimentos de baixo valor nutritivo, normalmente com elevado teor de parede celular, associado a baixo teor de PB. Na literatura, o teor de PB descrito para a casca de café é de aproximadamente $10 \%$ e o de FDN, de 49,50 a 77\% (Barcelos et al., 2001; Souza et al., 2001). Ressalta-se que grande parte do nitrogênio encontrado na casca de café está associada à parede celular, indisponível para os microrganismos ruminais.

Ao incluírem a casca de café em substituição ao milho no concentrado para vacas em lactação $(0,00 ; 8,75 ; 17,50$ e $26,25 \%$ da MS), Souza et al. (2003a,b) observaram decréscimo no coeficiente de digestibilidade dos nutrientes. O consumo de MS e a produção e composição do leite não foram alterados pelos níveis de casca de café, mas o menor custo com a alimentação e a maior margem bruta foram obtidos com os maiores níveis de casca de café. Assim, esses autores recomendaram a inclusão deste resíduo em até $26,25 \%$ de substituição ao milho no concentrado de vacas em lactação, o que representa $10,50 \%$ de casca de café na MS da dieta.
Considerando a necessidade de se estabelecer o limite de utilização da casca de café na dieta de vacas em lactação, realizou-se este trabalho para avaliar os efeito da inclusão de casca de café em substituição ao milho no concentrado sobre o consumo e a digestibilidade dos nutrientes, a produção e composição do leite e a economicidade da dieta.

\section{Material e Métodos}

O experimento foi realizado no Setor de Bovinocultura de Leite do Departamento de Zootecnia da Universidade Federal de Viçosa, na cidade de Viçosa - MG, no período de 29 de janeiro a 29 de março de 2003. Foram utilizadas 12 vacas da raça Holandesa Malhada de Preto, com peso médio de $570,75 \mathrm{~kg}$ e produção média de leite de $22,0 \mathrm{~kg} / \mathrm{dia}$. Os animais foram distribuídos em três quadrados latinos 4 x 4 , balanceados de acordo com o período de lactação de cada animal. O primeiro quadrado foi formado por vacas primíparas e o segundo e terceiro por vacas multíparas. Cada período experimental teve duração de 15 dias, os sete primeiros para adaptação e os demais para avaliação do consumo, da digestibilidade, da produção e da composição do leite.

Os tratamentos foram constituídos de quatro níveis de casca de café $(0 ; 12,5 ; 25,0$ e 37,5\%, com base na MS) em substituição ao milho do concentrado, correspondendo aos níveis de 0,$0 ; 5,0 ; 10,0$ e $15,0 \%$ da MS total da dieta (Tabela 1). A alimentação foi fornecida duas vezes ao dia (6h40 e 16h30), de modo que o concentrado foi misturado à silagem de milho no momento do fornecimento, mantendo-se a relação volumoso:concentrado de 60:40, com base na matéria seca. Diariamente, a quantidade de alimento foi ajustada, de modo que a proporção de sobras no cocho fosse mantida em 5 e $10 \%$ do total fornecido.

A composição bromatológica da silagem de milho, da casca de café e dos concentrados é descrita na Tabela 2.

A casca de café utilizada foi adquirida da Cooperativa dos Cafeicultores de Guaxupé, uma indústria beneficiadora, localizada no sul estado de Minas Gerais. Antes de ser misturada aos ingredientes do concentrado, a casca de café foi triturada em moinho com peneira de $1 \mathrm{~mm}$ (a mesma utilizada para moagem do milho). Na Tabela 3, encontra-se a composição bromatológica das dietas experimentais.

Os animais foram alojados em galpão coberto, com baias individuais do tipo tie stall, providas de piso de borracha com bebedouro automático e comedouros. As vacas foram ordenhadas mecanicamente, às $6 \mathrm{e}$ às $16 \mathrm{~h}$, efetuando-se o registro diário da produção de leite. Ao início e final de cada período experimental, após a ordenha da manhã, realizaram-se as pesagens dos animais para avaliação da variação no peso vivo. 
Tabela 1 - Proporção, com base na MS, dos ingredientes no concentrado

Table 1 - Ingredient composition of the concentrate (\% DM)

Ingrediente

Ingredient

Nível de casca de café

Coffee hulls levels

\begin{tabular}{|c|c|c|c|c|}
\hline & 0 & 5 & 10 & 15 \\
\hline Farelo de soja (Soybean meal) & 41,1 & 41,1 & 41,1 & 41,1 \\
\hline Milho (Corn) & 53,10 & 40,60 & 28,10 & 15,60 \\
\hline Casca de café (Coffee hulls) & - & 12,50 & 25,00 & 37,50 \\
\hline Uréia $^{1}$ (Urea) & 2,00 & 2,00 & 2,00 & 2,00 \\
\hline Fosfato bicálcico (Dicalcium phosphate) & 1,08 & 1,08 & 1,08 & 1,08 \\
\hline Calcário (Limestone) & 1,80 & 1,80 & 1,80 & 1,80 \\
\hline Sal comum (Salt) & 0,90 & 0,90 & 0,90 & 0,90 \\
\hline Premix mineral ${ }^{2}$ (Mineral premix) & 0,02 & 0,02 & 0,02 & 0,02 \\
\hline
\end{tabular}

${ }^{1}$ Corresponde à mistura uréia:sulfato de amônia, na proporção de 9:1 (It express urea:amonium sulfate, in the ratio of 9:1).

${ }^{2}$ Composição do premix mineral, \% (Composition of the mineral premix, \%): sulfato de zinco (zinc sulfate): 50,00 ; sulfato de cobre (copper sulfate): 41,66 ; sulfato de cobalto (cobalt sulfate): 2,78; selenito de sódio (sodium selenite): 2,78 ; iodato de potássio (potassium iodate): 2,78 .

Tabela 2 - Composição química e nutrientes digestíveis totais estimados (NDT EST) dos concentrados, da casca de café e da silagem de milho

Table 2 - Chemical composition and total digestible nutrients (TDN) of the concentrates, coffee hulls and corn silage

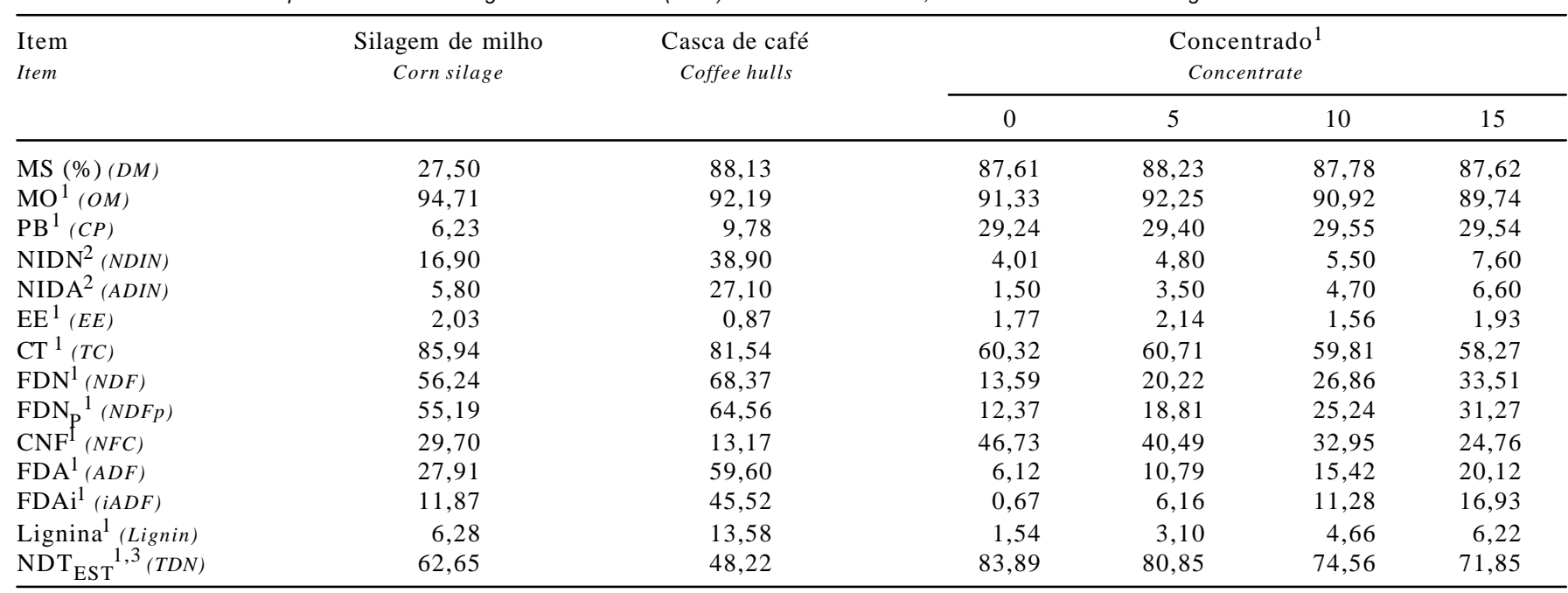

${ }^{1}$ Valores em porcentagem da MS; ${ }^{2}$ Valores em porcentagem do nitrogênio total; ${ }^{3}$ Estimado pelo NRC (2001).

${ }^{1}$ Values in DM basis; ${ }^{2}$ Values expressed as percentage of total nitrogen; ${ }^{3}$ Estimated according to the NRC (2001).

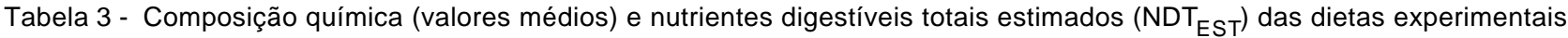
Table 3 - Chemical compositon (average values) and total digestible nutrients (TDN) of the experimental diets

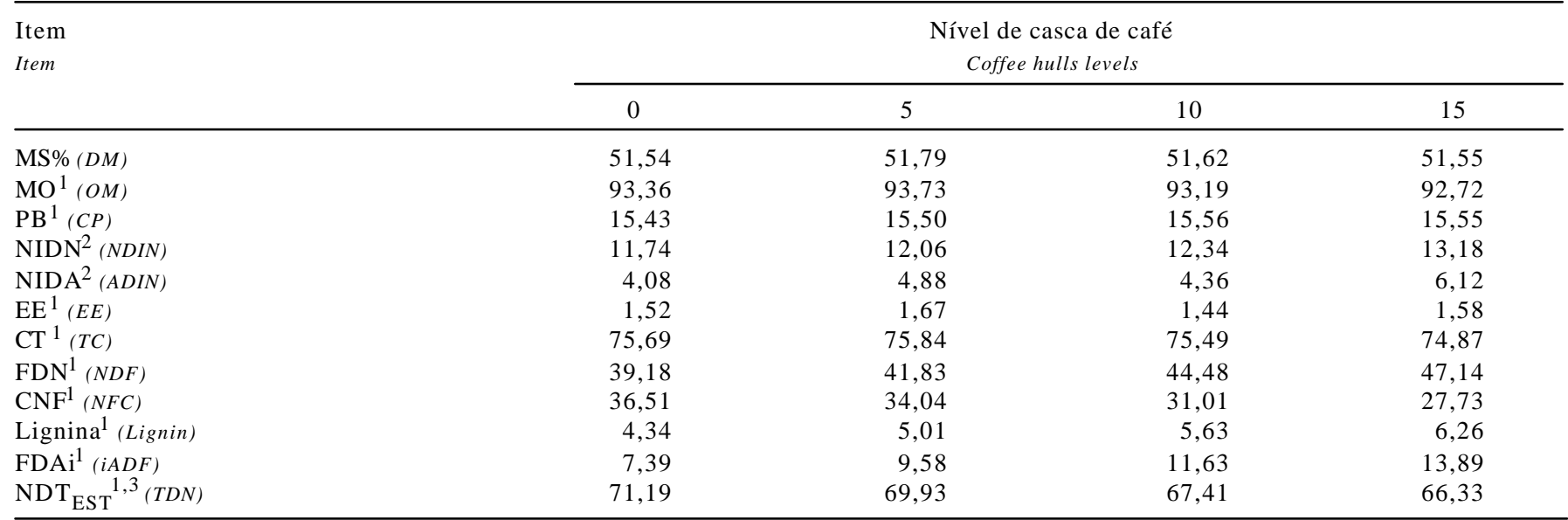

${ }^{1}$ Valores em porcentagem da MS; ${ }^{2}$ Valores em porcentagem do nitrogênio total; ${ }^{3}$ Estimado pelo NRC (2001).

1 Values in DM basis; ${ }^{2}$ Values expressed as percentage of total nitrogen; ${ }^{3}$ Estimated according to the NRC (2001). 
Durante os períodos de coleta, amostras dos alimentos e das sobras foram coletadas e acondicionadas em sacos plásticos, que foram devidamente identificados e armazenados emfreezer para análises laboratoriais. Amostras de leite da $2 \underline{\mathrm{a}} \mathrm{e} 1 \underline{\mathrm{a}}$ ordenhas do $12 \underline{\mathrm{o}} \mathrm{e} 13 \underline{\mathrm{o}}$ dias, respectivamente, de cada período experimental, foram compostas proporcionalmente de acordo com a produção de leite.

A coleta de amostras de fezes para determinação da digestibilidade dos nutrientes foi realizada às 7, 9, 11, 13, 15 e $17 \mathrm{~h}$, respectivamente, do $9 \underline{0}$ ao 14 o dia de cada período experimental, em intervalos de 26 horas. A estimativa da excreção fecal foi feita utilizando-se a fibra em detergente ácido indigestível (FDAi) como indicador, conforme Cochran et al. (1986), com algumas alterações. Neste procedimento, as amostras dos ingredientes do concentrado, da casca de café, da silagem de milho, das sobras e das fezes, previamente secos e moídos (1 mm), foram acondicionadas em sacos Ankon (Filter bags F57) e incubadas no rúmen durante 144 horas. O material remanescente da incubação foi previamente lavado com água e submetido à extração com detergente ácido, cujo resíduo foi considerado FDAi.

As amostras de sobras e da silagem de milho foram secas em estufa ventilada a $65^{\circ} \mathrm{C}$ por 72 horas, para se proceder à moagem. Os ingredientes da ração e o material seco em estufa foram triturados em moinho tipoWilleycom peneira de 1,0 mm, acondicionados em vidros com tampa e armazenados para posteriores análises laboratoriais.

As análises de MS, MO, PB, FDN, FDA, lignina, EE, NIDA e NIDN foram realizadas segundo procedimentos descritos por Silva \& Queiroz (2002). Os teores de carboidratos totais (CT) foram calculados conforme proposto por Sniffen et al. (1992), em que CT $=100-(\% \mathrm{~PB}+\% \mathrm{EE}$ $+\% \mathrm{CZ})$, e os de $\mathrm{CNF}$, pela fórmula $\mathrm{CNF}=\mathrm{CT}-\mathrm{FDN}$.

O nitrogênio total nas amostras de leite foi determinado segundo procedimentos descritos por Silva et al. (1997). Os teores de sólidos totais foram quantificados pela secagem de amostras de leite em estufa a $105^{\circ} \mathrm{C}$ e os de gordura foram determinados em aparelho modelo MK 2.5. A produção de leite corrigida para $4 \%$ de gordura (PLC) foi obtida pela equação citada pelo NRC (2001), em que PLC $=0,4 * \mathrm{PL}+$ $15^{*} \mathrm{G}(\mathrm{G}=\mathrm{kg}$ de gordura $)$.

A concentração do $\mathrm{NDT}_{\mathrm{EST}}$ (nutrientes digestíveis totais estimados) dos alimentos, dos concentrados e das dietas totais foi calculada conforme equações descritas pelo NRC (2001). Os valores de NDT calculados para as diferentes dietas foram obtidos pela equação: NDT $=$ PBD + EED x 2,25 + FDND + CNFD.

Para análise da economicidade, foram considerados o consumo pelos animais, a produção de leite e o preço dos alimentos e do leite. A receita com a produção de leite por vaca foi representada pelo produto entre a produção de leite e o preço do leite, em que o preço por litro de leite correspondeu ao preço pago pelo leite $\mathrm{C}$ aos produtores de Minas Gerais em 2004. O custo com alimentação, por vaca, foi representado pelo produto dos preços dos alimentos utilizados (silagem de milho, concentrado e casca de café) pelo seu respectivo consumo de matéria natural. O custo por litro de leite produzido foi calculado dividindo-se o s gasto s com alimentação por vaca pela produção de leite por vaca. O saldo com alimentação foi obtido pela diferença entre o valor da produção de leite e o s gasto s com alimentação.

Os dados foram submetidos às análises de variância e de regressão utilizando-se o programa SAEG, versão 7.1 (UFV, 1997). As variáveis foram interpretadas estatisticamente por meio de análises de variância e regressão, a 5\% de probabilidade.

\section{Resultados e Discussão}

Na Tabela 4 são apresentados os consumos médios dos nutrientes com suas respectivas equações de regressão. Com exceção do consumo de EE, o consumo dos demais nutrientes foi influenciado $(\mathrm{P}<0,05)$ pelos níveis de casca de café nas dietas.

O consumo de MS em $\mathrm{kg} / \mathrm{dia}$ e $\mathrm{g} / \mathrm{kg}^{0,75}$ diminuiu linearmente $(\mathrm{P}<0,05)$ com os níveis de casca de café, enquanto o consumo de MS (\%PV) ajustou-se a um modelo quadrático, estimando-se valor máximo de $3,40 \%$ de PV para o nível de 3,81\% de casca de café na MS total. Na dieta com maior proporção de casca de café $(15 \%)$, os animais consumiram em média 2,68 kg/dia de casca. Estes resultados diferem dos encontrados em outros trabalhos, como os realizados por Barcelos (1996) e Souza et al. (2003a), em que os consumos médios de casca de café na dieta com maior proporção deste ingrediente foram de 1, 65 e $1,96 \mathrm{~kg} / \mathrm{dia}$, respectivamente. O consumo de MS total sugerido pelo NRC (2001) para os animais utilizados neste experimento é de $18,13 \mathrm{~kg} /$ dia e, portanto, apenas na dieta com $15,0 \%$ de casca de café, esse valor foi $6 \%$ menor (Tabela 4).

A redução no CMS pode estar associada ao maior teor de FDN e, principalmente, ao alto teor de lignina $(13,58 \%)$ encontrado na casca de café. Em dietas com teores mais altos de FDN, o CMS pode ser limitado pelo enchimento ruminal (NRC, 2001), como resultado da menor taxa de passagem pelo rúmen-retículo. Allen (2000) mostrou que, em dietas com FDN acima de $25 \%$, pode haver redução no CMS com o aumento do conteúdo de FDN. 
Tabela 4 - Médias, coeficientes de variação (CV), equações de regressão e coeficientes de determinação $\left(R^{2}\right)$ obtidos para os consumos diários de nutrientes da dieta em função dos níveis de casca de café no concentrado

Table 4 - Means, coefficents of variation (CV), regression equations and coefficients of determination ( $R^{2}$ ) obtained for daily nutrient intakes according to the dietary levels of coffee hulls

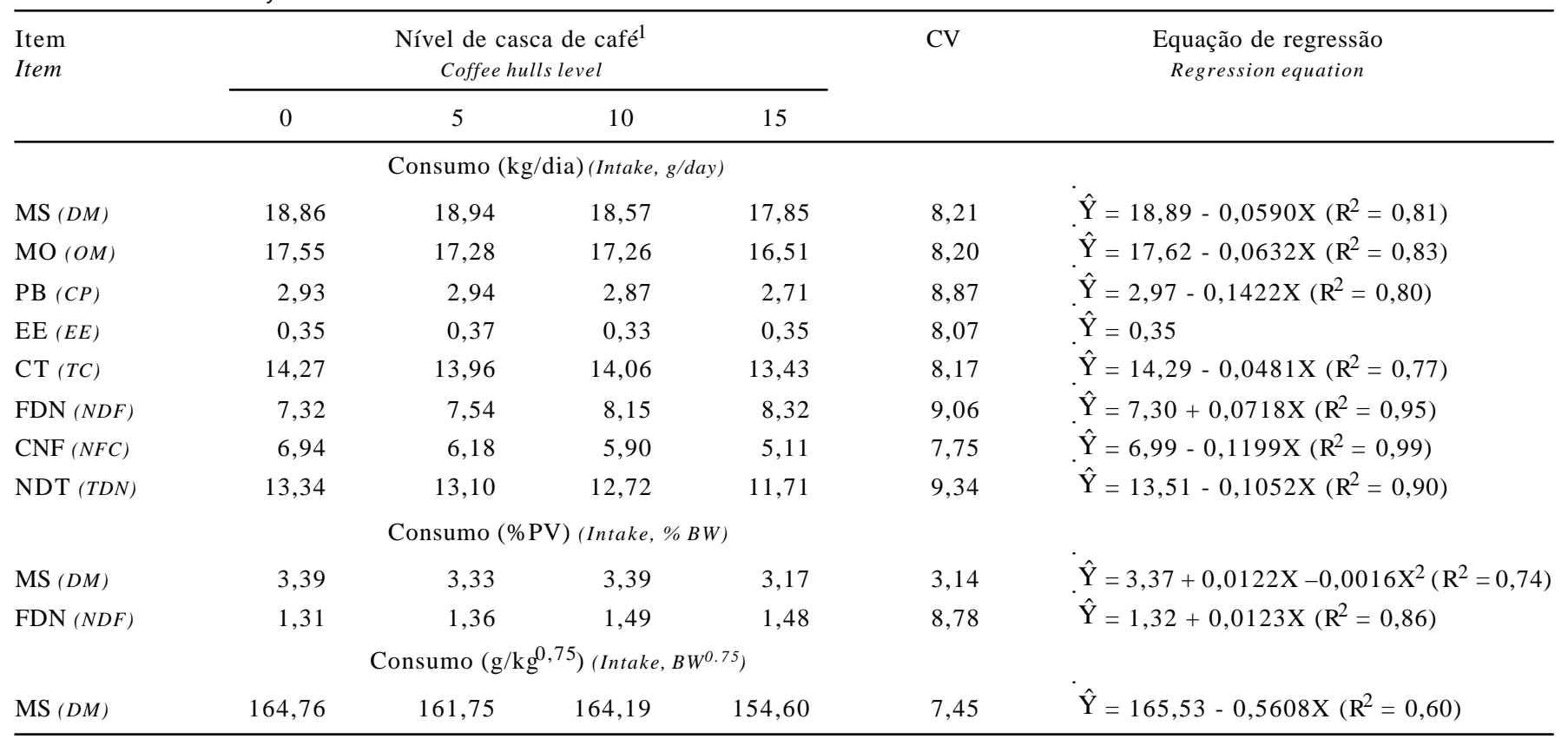

1 Porcentagem de casca de café na dieta (base da MS) (Proportion of coffee hulls in the diet, DM basis).

Outro componente da casca de café que afeta negativamente o consumo é a cafeína (Vargas et al., 1982). Segundo Cabezas (1976), a presença de níveis superiores a $0,12 \%$ de cafeína provoca efeitos adversos no consumo e na utilização de alimentos por bovinos. É possível que a cafeína, por ser um composto fenólico, aumente a mobilização de ácidos graxos livres para o plasma sangüíneo, provocando redução no apetite e no consumo de alimentos (Braham et al., 1973).

Apesar de as dietas terem sido isoprotéicas, o consumo de $\mathrm{PB}$ reduziu linearmente $(\mathrm{P}<0,05)$ com a inclusão da casca de café, como conseqüência da menor ingestão de MS, ocorrendo decréscimo de 63,2 g para cada $1,0 \%$ de casca adicionada. O consumo de EE não foi influenciado pela adição da casca de café e justifica-se pelo decréscimo no consumo de MS com o aumento da inclusão desse subproduto na dieta. Esse resultado difere do encontrado por Souza et al. (2003b), que observaram decréscimo no consumo de EE com a redução do teor de EE na casca de café.

Para os consumos de CT, CNF e FDN, estimaram-se decréscimos de 48,1 e 119,9 g/dia e acréscimo de 71,8 g/dia, respectivamente, para cada unidade de casca adicionada. Este comportamento está relacionado ao maior conteúdo de FDN e ao menor conteúdo de CNF da casca de café em relação ao milho no concentrado.
O consumo de NDT decresceu de forma linear $(\mathrm{P}<0,05)$ com a adição de níveis crescentes de casca de café, estimando-se redução de 105,2 g/dia por unidade de casca adicionada como resultado da redução no consumo de CNF, que possui alta digestibilidade e valor energético, e do simultâneo aumento no consumo de FDN, que influencia negativamente a disponibilidade dos nutrientes, em virtude de sua lenta e incompleta digestão no sistema gastrintestinal (Jung \& Allen, 1995).

O consumo de NDT, apesar do decréscimo, ainda foi maior que o recomendado pelo NRC (1989), que sugere consumo de $11,23 \mathrm{~kg} /$ dia para vacas com peso médio de $550 \mathrm{~kg}$ produzindo $22,55 \mathrm{~kg}$ leite/dia com $3,5 \%$ de gordura.

Os coeficientes médios de digestibilidade aparente da MS, MO e dos nutrientes e a concentração de nutrientes digestíveis totais, com suas respectivas equações de re gressão, encontram-se na Tabela 5.

Os coeficientes de digestibilidade da MS, MO e PB apresentaram resposta linear decrescente $(\mathrm{P}<0,05)$ com a adição de casca às dietas, estimando-se, respectivamente, reduções de 0,$3755 ; 0,3487$ e 0,3120 unidades percentuais para cada unidade de casca de café adicionada. Por sua vez, a digestibilidade de EE aumentou linearmente $(\mathrm{P}<0,05)$, estimando-se acréscimo de 0,4217 unidades para cada unidade de casca adicionada. 
Tabela 5 - Médias, coeficientes de variação (CV), equações de regressão e coeficientes de determinação $\left(R^{2}\right)$ obtidos para os coeficientes de digestibilidade dos nutrientes da dieta em função dos níveis de casca de café no concentrado

Table 5 - Means, coefficents of variation (CV), regression equations and coefficients of determination ( $R^{R}$ ) obtained for apparent total tract nutrient digestibilities according to the dietary levels of coffee hulls

\begin{tabular}{|c|c|c|c|c|c|c|}
\hline \multirow[t]{2}{*}{$\begin{array}{l}\text { Item } \\
\text { Item }\end{array}$} & \multicolumn{4}{|c|}{$\begin{array}{c}\text { Nível de casca de café } \\
\text { Coffee hulls level }\end{array}$} & \multirow[t]{2}{*}{$\mathrm{CV}$} & \multirow[t]{2}{*}{$\begin{array}{c}\text { Equação de regressão } \\
\text { Regression equation }\end{array}$} \\
\hline & 0 & 5 & 10 & 15 & & \\
\hline $\mathrm{MO}(O M)$ & 74,18 & 73,89 & 71,93 & 69,03 & 4,07 & $\hat{\mathrm{Y}}=74,87-0,3487 \mathrm{X}\left(\mathrm{R}^{2}=0,90\right)$ \\
\hline $\mathrm{PB}(C P)$ & 76,16 & 75,12 & 72,48 & 71,84 & 4,07 & $\hat{\mathrm{Y}}=76,24-0,3120 \mathrm{X}\left(\mathrm{R}^{2}=0,95\right)$ \\
\hline $\mathrm{FDN}(N D F)$ & 64,38 & 62,57 & 59,67 & 57,49 & 8,38 & $\hat{\mathrm{Y}}=64,57-0,4714 \mathrm{X}\left(\mathrm{R}^{2}=0,99\right)$ \\
\hline $\mathrm{CNF}(N F C)$ & 82,75 & 85,98 & 87,26 & 84,84 & 4,14 & $\hat{Y}=82,66+0,9994 X-0,0565 X^{2}\left(R^{2}=0,99\right)$ \\
\hline $\mathrm{NDT}(T D N)$ & 70,73 & 71,05 & 68,69 & 65,78 & 4,16 & $\hat{Y}=71,6357-0,3437 X\left(R^{2}=0,84\right)$ \\
\hline
\end{tabular}

${ }^{1}$ Valores em porcentagem da MS (Values in DM basis).

A redução no consumo de CNF, os quais apresentam disponibilidade rápida e praticamente completa no sistema digestivo de ruminantes (Allen \& Mertens, 1987), associada às diferenças quantitativas entre os constituintes da parede celular do milho e da casca de café (Tabela 2), pode ser considerada principal responsável pela redução na digestibilidade da MS à medida a casca de café foi adicionada às dietas.

Os resultados de digestibilidade da proteína bruta podem ser explicados pelo aumento da fração nitrogenada aderida à parede celular (NIDA e NIDN) das dietas com maiores níveis de casca, diminuindo a disponibilidade de nitrogênio para os microrganismos ruminais.

A digestibilidade dos CNF apresentou comportamento quadrático $(\mathrm{P}<0,05)$, estimando-se digestibilidade máxima de $87,08 \%$ com a adição de $8,87 \%$ de casca de café. As digestibilidades dos CT e da FDN decresceram linearmente $(\mathrm{P}<0,05)$ com a inclusão de casca, estimando-se reduções de 0,3760 e 0,4714 unidades percentuais para cada $1 \%$ de casca adicionada, respectivamente. A composição química da FDN (proporção de hemicelulose, celulose e lignina) afeta a digestibilidade da fração FDN (NRC, 2001). A menor digestibilidade dos $\mathrm{CT}$ está relacionada à menor digestibilidade daFDN, em razão dos altos teores de lignina (Tabela 2) da casca de café, que limitam a digestão dos polissacarídeos da parede celular no rúmen (Jung \& Allen, 1995). Souza et al. (2001) observaram baixos valores para a digestibilidade in vitro da FDN, registrando valor médio de $28,9 \%$.

Observou-se efeito linear $(\mathrm{P}<0,05)$ dos níveis de casca sobre o teor de NDT, estimando-se decréscimo de 0,3437 unidades para cada $1 \%$ de cada adicionada. A redução na digestibilidade aparente dos nutrientes, somada à menor ingestão de CNF, contribuiu para a redução do conteúdo de NDT das dietas.

As produções de leite corrigidas ou não para $4,0 \%$ de gordura, os teores de gordura, proteína, sólidos totais e extrato seco desengordurado e a variação do peso vivo (VPV) não foram influenciados pelos níveis de casca de café nas dietas (Tabela 6). Estes resultados estão de acordo com os encontrados por Souza et al. (2003a), ao testarem a inclusão da casca de café em até $10 \%$ da MS total na dieta de vacas com produção média de $23,43 \mathrm{~kg} / \mathrm{leite} /$ dia.

Mesmo com o decréscimo no consumo e na digestibilidade dos nutrientes, não houve influência $(P>0,05)$ das dietas sobre a produção de leite e a VPV, o que pode estar relacionado ao fato de os animais terem suprido suas exigências de NDT em todas as dietas, conforme relatado, indicando a possibilidade de substituição de $15,0 \%$ do milho pela casca de café na dieta de vacas em lactação. O NRC (1989) considera exigência de $0,322 \mathrm{~kg}$ de NDT para cada kg de leite produzido com 3,5\% de gordura, para vacas com peso médio de $550 \mathrm{~kg}$. Considerando o consumo de NDT acima das exigências e o decréscimo linear na eficiência de produção de leite, poderia ser detectado o nível de casca de café na dieta que limitaria a produção de leite caso os animais tivessem potencial para maior produção de leite.

Os dados relativos ao preço de produtos e insumos, aos resultados da produção, ao consumo das dietas, ao valor da produção de leite, aos gastos com alimentação e ao saldo com alimentação encontram-se na Tabela 7.

Embora o consumo de matéria seca tenha sido influenciado pelos níveis de casca de café, a diferença entre o 
Tabela 6 - Médias, coeficientes de variação (CV), equações de regressão e coeficientes de determinação $\left(R^{2}\right)$ para as produções de leite corrigidas (PLC) ou não (PL) para 3,5\% de gordura, a eficiência, os teores de gordura, proteína, extrato seco total (EST) e extrato seco desengordurado (ESD) e variação no peso vivo (VPV) em função dos níveis de casca de café no concentrado

Table 6 - Means, coefficents of variation (CV), regression equations and coefficients of determination ( $\left.P^{2}\right)$ obtained for $3.5 \%$ fat corrected milk (FCM), milk yield (MY), efficiency, contents and yields of fat, protein, total solids (TS) and solids nonfat (SNF), and body weight change (BWC) according to the dietary levels of coffee hulls

\begin{tabular}{|c|c|c|c|c|c|c|}
\hline \multirow[t]{2}{*}{$\begin{array}{l}\text { Item } \\
\text { Item }\end{array}$} & \multicolumn{4}{|c|}{$\begin{array}{c}\text { Nível de casca de café } \\
\text { Coffee hulls level }\end{array}$} & \multirow[t]{2}{*}{$\mathrm{CV}$} & \multirow[t]{2}{*}{$\begin{array}{l}\text { Equação de regressão } \\
\text { Regression equation }\end{array}$} \\
\hline & 0 & 5 & 10 & 15 & & \\
\hline PLG (kg/vaca) $F C M(k g / c o w)$ & 21,15 & 21,74 & 21,76 & 21,82 & 7,31 & $\hat{Y}=21,62$ \\
\hline Eficiência Efficiency & 0,88 & 0,84 & 0,86 & 0,81 & 8,16 & $\hat{\mathrm{Y}}=0,87-0,3907 \mathrm{X}\left(\mathrm{R}^{2}=0,0,75\right)$ \\
\hline Proteína (\%) Protein (\%) & 3,35 & 3,57 & 3,41 & 3,30 & 10,31 & $\hat{\mathrm{Y}}=3,41$ \\
\hline Proteína (g) Protein (g) & 743,99 & 815,62 & 772,14 & 744,92 & 14,56 & $\bar{Y}=769,17$ \\
\hline Sólidos totais (\%) TS (\%) & 12,91 & 12,65 & 12,66 & 12,57 & 4,30 & $\hat{Y}=12,70$ \\
\hline Sólidos totais $(\mathrm{kg}) T S(\mathrm{~kg})$ & 2,83 & 2,86 & 2,86 & 2,83 & 9,52 & $\hat{Y}=2,85$ \\
\hline
\end{tabular}

${ }^{1}$ Valores em porcentagem da MS (Values in DM basis).

Tabela 7 - Receitas, custos com alimentação e saldo obtidos em função dos níveis de casca de café no concentrado Table 7 - Income, feeding costs, and balance according to the dietary levels coffee hulls

\begin{tabular}{|c|c|c|c|c|}
\hline \multirow[t]{2}{*}{$\begin{array}{l}\text { Componentes de receitas, custos e saldos } \\
\text { Income, cost, and balance }\end{array}$} & \multicolumn{4}{|c|}{$\begin{array}{l}\text { Nível de casca de café } \\
\text { Coffee hulls levels }\end{array}$} \\
\hline & 0 & 5 & 10 & 15 \\
\hline \multicolumn{5}{|l|}{ 1. Preços de produtos e insumos (Supplies and products prices) } \\
\hline $\begin{array}{l}\text { Preço bruto do leite }(\mathrm{R} \$ / \mathrm{litro})^{1} \text { (Gross milk price, } R \$ / \text { liter) } \\
\left.\text { Preço do concentrado }(\mathrm{R} \$ / \mathrm{kg})^{2} \text { (Concentrate price, } R \$ / \text { liter }\right) \\
\left.\text { Preço do milho }(\mathrm{R} \$ / \mathrm{kg} \mathrm{MN})^{3} \text { (Corn grain price, } R \$ / \mathrm{kg} N M\right) \\
\text { Preço da casca de café }(\mathrm{R} \$ / \mathrm{kg} \mathrm{MN})(\text { Coffee hulls price, } R \$ / \mathrm{kg} N M) \\
\text { Preço da silagem de milho }(\mathrm{R} \$ / \mathrm{kg} \mathrm{MN}) \text { (Corn silage price, } R \$ / \mathrm{kg} D M) \\
\text { Preço relativo da casca de café (\% do preço do milho) } \\
\text { Proportional coffee hulls price, \% of corn price }\end{array}$ & $\begin{array}{c}0,480 \\
0,538 \\
0,360 \\
0,056 \\
0,050 \\
15,0\end{array}$ & $\begin{array}{c}0,480 \\
0,500 \\
0,360 \\
0,056 \\
0,050 \\
15,0\end{array}$ & $\begin{array}{c}0,480 \\
0,461 \\
0,360 \\
0,056 \\
0,050 \\
15,0\end{array}$ & $\begin{array}{c}0,480 \\
0,423 \\
0,360 \\
0,056 \\
0,050 \\
15,0\end{array}$ \\
\hline \multicolumn{5}{|l|}{ 2. Resultados da produção (Production data) } \\
\hline Produção de leite por vaca (kg/dia) (Milk yield per cow, kg/day) & 22,08 & 22,68 & 22,67 & 22,75 \\
\hline \multicolumn{5}{|l|}{ 3. Consumo médio das dietas (MN) (Average dietary intake, $N M)$} \\
\hline $\begin{array}{l}\text { Consumo silagem de milho }(\mathrm{kg} / \mathrm{dia}) \text { (Corn silage intake, } \mathrm{kg} / \text { day) } \\
\text { Consumo concentrado(kg/dia) (Concentrate intake, } \mathrm{kg} / \text { day) } \\
\text { Consumo total }(\mathrm{kg} / \mathrm{dia}) \text { (Total intake, } \mathrm{kg} / \text { day) }\end{array}$ & $\begin{array}{l}41,15 \\
8,61 \\
49,76\end{array}$ & $\begin{array}{c}41,32 \\
8,59 \\
49,91\end{array}$ & $\begin{array}{c}40,52 \\
8,46 \\
48,98\end{array}$ & $\begin{array}{c}38,95 \\
8,15 \\
47,09\end{array}$ \\
\hline \multicolumn{5}{|l|}{ 4. Valor da produção de leite (Milk yield gross income) } \\
\hline $\begin{array}{l}\text { Por vaca/dia (R } \$ / \mathrm{vaca} / \mathrm{dia}) \text { (Per cow/day, } R \$ / \text { cow/day) } \\
\text { Por litro (R } \$ / \text { litro) (Per liter, } R \$ / \text { liter) }\end{array}$ & $\begin{array}{c}10,598 \\
0,480\end{array}$ & $\begin{array}{c}10,886 \\
0,480\end{array}$ & $\begin{array}{c}10,882 \\
0,480\end{array}$ & $\begin{array}{c}10,920 \\
0,480\end{array}$ \\
\hline \multicolumn{5}{|l|}{ 5. Gastos com alimentação (Feeding cost) } \\
\hline $\begin{array}{l}\text { Por vaca/dia (R } \$ / \mathrm{vaca} / \mathrm{dia})(\text { Per cow/day, } R \$ / \text { cow/day) } \\
\text { Por litro (R } \$ / \text { litro) (Per liter, } R \$ / \text { liter) }\end{array}$ & $\begin{array}{l}6,894 \\
0,312\end{array}$ & $\begin{array}{l}6,564 \\
0,289\end{array}$ & $\begin{array}{l}6,136 \\
0,271\end{array}$ & $\begin{array}{l}5,598 \\
0,248\end{array}$ \\
\hline \multicolumn{5}{|l|}{ 6. Saldo com alimentação(Feeding balance, 4-5) } \\
\hline $\begin{array}{l}\text { Vaca }(\mathrm{R} \$ / \mathrm{vaca} / \mathrm{dia})(\text { Cow }, R \$ / \text { cow/day }) \\
\text { Leite }(\mathrm{R} \$ / \text { litro) (Milk, } R \text { /liter })\end{array}$ & $\begin{array}{l}3,705 \\
0,168\end{array}$ & $\begin{array}{l}4,322 \\
0,191\end{array}$ & $\begin{array}{l}4,746 \\
0,209\end{array}$ & $\begin{array}{l}5,322 \\
0,234\end{array}$ \\
\hline
\end{tabular}

${ }^{1}$ Preço médio do leite C recebido pelos produtores de Minas Gerais em 2003.

2 Preços médios dos ingredientes em 2003 em Minas Gerais.

${ }^{3}$ Custos médios do leite produzido na região da Zona da Mata, MG.

${ }_{1}^{1}$ Average price of type C milk in Minas Gerais (MG), in 2003.

${ }^{2}$ Average price of concentrate ingredients during the year of 2003 in Minas Gerais.

${ }^{3}$ Average production cost of milk producers in the Zona da Mata, MG region. 
consumo de matéria natural nos níveis 0 e $15 \%$ de casca de café foi de 2,67 kg/animal/dia. Houve aumento no valor da produção de leite com a inclusão da casca de café. Os gastos com alimentação reduziram linearmente com a inclusão da casca de café na dieta, em razão do menor preço de MS da casca de café em relação ao milho. A produção de leite não foi influenciada pelos níveis de casca de café e, portanto, o maior saldo no nível $15 \%$ está relacionado ao menor custo desta dieta.

Como não foram observadas alterações significativas na produção de leite e no peso dos animais, a substituição da casca de café (resíduo da agroindústria) pelo milho (alimento nobre) deve ser feita com cautela, pois influenciou negativamente o consumo e a digestibilidade dos nutrientes, observando-se consumo de NDT maior que o sugerido pelo NRC (1989).

\section{Conclusões}

A substituição do milho do concentrado por casca de café pode ser feita em até $15 \%$ da MS total em dietas à base de silagem de milho para vacas produzindo diariamente, em média, 22,55 kg de leite, ou seja, a decisão de incluir a casca de café na dieta de vacas em lactação depende apenas de fatores econômicos.

\section{Literatura Citada}

ALLEN, M.S. Effects of diet on short-term regulation of feed intake by lactating dairy cows. Journal of Dairy Science, v.76, p.485-498, 2000.

ALLEN, M.S.; MERTENS, D.R. Evaluating constraints on fiber digestion by rumen microbes. Journal Nutrition, v.118, p.261-270, 1987.

ASSOCIAÇÃO BRASILEIRA DA INDÚSTRIA DE CAFÉ - ABIC. Disponível em: <www.abic.com.br/estat_pagricola.html> Acesso em: 10/03/2003.

BARCELOS, A.F.; ANDRADE, I.F.; Von TIESEHOUSEN, I.M.E. et al. Aproveitamento da casca de café na alimentação de vacas em lactação. In: REUNIÃO ANUAL DA SOCIEDADE BRASILEIRA DE ZOOTECNIA, 33., 1996, Fortaleza.Anais... Fortaleza: Sociedade Brasileira de Zootecnia, 1996. p.128-130.

BARCELOS, A.F.; ANDRADE, I.F; von TIESENHAUSEN, I.M.W.V. et al. Aproveitamento da casca de café na alimentação de novilhos confinados - resultados do primeiro ano. Revista Brasileira de Zootecnia, v.26, n.6, p.2308-1214, 1997.

BARCELOS, A.F.; PAIVA, P.C.A.; PEREZ, J.R.O. Parâmetros bromatológicos da casca e polpa desidratada de café (Coffea arábica L.) armazenadas em diferentes períodos de armazenamento. In: REUNIÃO ANUAL DA SOCIEDADE BRASILEIRA DE ZOOTECNIA., 39., 2001, Piracicaba. Anais... Piracicaba: Sociedade Brasileira de Zootecnia, 2001 (CD-ROM).

BRAHAM, J.E.; JARQUIN, R., GONZALEZ, J.M. et al. Pulpa y pergamino de café. III. Utilización de la pulpa de cafe en forma de ensilaje. Archivos Latinoamericanos de Nutrición, v.23, n.3, p.389-388, 1973.

CABEZAS, M.T. Valor nutritivo de la pulpa de café para ganado de corte. Agricultura en El Salvador, v.3, n.15, p.25-39, 1976.
CHOCHRAN, R.C., ADAMS, D.C., WALlACE, J.D. et al. Predicting digestibility diets with internal markers: Evaluation of four potential markers. Journal of Animal Science, v.63, p.1476-1483, 1986.

DUTRA, A.R.; QUEIROZ, A.C.; PEREIRA, J.C. et al. Efeitos dos níveis de fibra e das fontes de proteínas sobre a síntese de compostos nitrogenados microbianos em novilhos. Revista Brasileira de Zootecnia, v.26, n.4, p.797-805, 1997.

JUNG, H.G.; ALLEN, S. Characteristics of plant cell walls affecting intake and digestibility of forages by ruminants. Journal of Dairy Science, v.73, n.9, p.2774-2790, 1995.

MATOS, L.L. Perspectivas em alimentação e manejo de vacas em lactação. In: REUNIÃO ANUAL DA SOCIEDADE BRASILEIRA DE ZOOTECNIA, 32., 1995, Brasília. Anais... Brasília: Sociedade Brasileira de Zootecnia, 1995. p.147-155.

NATIONAL RESEARCH COUNCIL - NRC. Nutrient requirements of dairy cattle. 6.ed. Washington, D.C.: National Academy Press, 1989. 158p.

NATIONAL RESEARCH COUNCIL - NRC. Nutrient requirements of dairy cattle. 7.ed. Washington, D.C.: National Academy Press, 2001. 381p.

ORGANIZAÇÃO DAS COOPERATIVAS BRASILEIRAS - OCB. Disponível em: <www.ocb.org.br/Coop_na_midia/fevereiro/ a2003-m02-d03-a.htm> Acesso em: 10/03/2003.

REIS, R.P.; MEDEIROS, A.L.; MONTEIRO, L.A. Custos de produção da atividade leiteira na região Sul de Minas Gerais. Lavras: Universidade Federal de Lavras, 2001. 13p.

SIGNORETTI, R.D.; CASTRO, A.C.G.; COELHO DA SILVA J.F. et al. Avaliação do farelo de gérmen de milho na alimentação de bezerros de raças leiteiras. Revista Brasileira de Zootecnia, v.26, n.3, p.616-622, 1997.

SILVA, D.J.; QUEIROZ, A.C. Análise de alimentos (Métodos químicos e biológicos). Viçosa, MG: Universidade Federal de Viçosa, 2002. 235p.

SILVA, P.H.F; PEREIRA, D.B.C.; OLIVEIRA, L.L. et al. Físicoquímica do leite e derivados - métodos analíticos. Juiz de Fora: ILCT/EPAMIG, 1997. 190p.

SNIFFEN, C.J.; O'CONNOR, J.D.; Van SOEST, P.J. et al. A net carbohydrate and protein system for evaluating cattle diets: II. Carbohydrate and protein availability. Journal of Animal Science, v.70, n.10, p.3562-3577, 1992.

SOUZA, A.L.; GARCIA, R.; PEREIRA, O.G. et al. Composição químico-bromatológica da casca de café tratada com amônia anidra e sulfeto de sódio. Revista Brasileira de Zootecnia, n.30, v.3, p.983-991, 2001 (supl.1).

SOUZA, A.L.; GARCIA, R.; ROCHA, F.C. et al. Casca de café em dietas de vacas: consumo e produção de leite. In: REUNIÃO ANUAL DA SOCIEDADE BRASILEIRA DE ZOOTECNIA, 40., 2003, Santa Maria. Anais... Santa Maria: Sociedade Brasileira de Zootecnia, 2003a. (CD-ROM)

SOUZA, A.L.; GARCIA, R.; BERNARDINO, F.S. et al. Digestibilidade de dietas com diferentes níveis de casca de café fornecidas para vacas em lactação. In: REUNIÃO ANUAL DA SOCIEDADE BRASILEIRA DE ZOOTECNIA, 40., 2003, Santa Maria. Anais... Santa Maria: Sociedade Brasileira de Zootecnia, 2003b. (CD-ROM)

SOUZA, A.L.; GARCIA, R.; BERNARDINO, F.S. et al. Casca de café em dietas de novilhas: consumo e digestibilidade dos nutrientes. In: REUNIÃO ANUAL DA SOCIEDADE BRASILEIRA DE ZOOTECNIA, 39., 2002, Recife. Anais... Recife: Sociedade Brasileira de Zootecnia, 2002. (CD-ROM)

SOUZA, A.L.; GARCIA, R.; BERNARDINO, F.S. et al. Casca de café em dietas de carneiros: consumo e digestibilidade dos nutrientes. In: REUNIÃO ANUAL DA SOCIEDADE BRASILEIRA DE ZOOTECNIA, 39., 2002, Recife. Anais... Recife: Sociedade Brasileira de Zootecnia, 2002. (CD-ROM)

SOUZA, A.L.; BERNARDINO, F.S.; GARCIA, R. et al. Valor nutritivo da silagem de capim-elefante (Pennisetum purpureum Schum.) com diferentes níveis da casca de café. Revista Brasileira de Zootecnia, v.32, n.4, p.828-833, 2003. 
TOWNSEND, C.R.; MAGALHÃES, J.A.; COSTA, N.L. et al. Utilização da casca de café na alimentação de ovinos deslanados. In: REUNIÃO ANUAL DA SOCIEDADE BRASILEIRA DE ZOOTECNIA, 35., 1998, Botucatu. Anais... Botucatu: Sociedade Brasileira de Zootecnia, 1998. p.149-151.

VILELA, F.G. Uso da casca de cafémelosa em diferentes níveis na alimentação de novilhos confinados. Lavras: Universidade Federal de Lavras, 1999. 46p. Dissertação (Mestrado em Zootecnia) - Universidade Federal de Lavras, 1999.

UNIVERSIDADE FEDERAL DE VIÇOSA - UFV. 1997. SAEG Sistema de análises estatísticas e genéticas. Versão 7.1. Viçosa, MG. 150p. (Manual do usuário).
VALADARES FILHO, S.C.; ROCHA JR., V.R.; CAPPELLE, E.R. Tabelas brasileiras de composição de alimentos para bovinos. Viçosa, MG: Universidade Federal de Viçosa, 2001. 297p. VARGAS, E.; CABEZAS, M.T.; MURILO, B. et al. Efecto de altos niveles de pulpa de cafe de deshidratada sobre el crecimieno y adaptación de novillos jóvenes. Archivos Latinoamericanos de Nutrición, v.32, n.4, p.972-989, 1982.

Recebido: 11/03/05 Aprovado: 09/05/06 